\title{
Concessões nas Unidades de Conservação do Estado de São Paulo: reflexões, oportunidades e desafios
}

\section{Tourism Concessions in Protected Areas of São Paulo state (Brazil): reflections, opportunities and challenges}

\author{
Alessandra Freire Reis, Odaléia Telles Marcondes Machado Queiroz
}

\section{RESUMO}

A discussão sobre a concessão das Unidades de Conservação é extremamente importante e tem gerado polêmica no Estado de São Paulo, devido à aprovação da Lei № 16.260, de 29 de junho de 2016, que "autoriza a Fazenda do Estado a conceder a exploração de serviços ou o uso, total ou parcial, de áreas em próprios estaduais". A pesquisa e o debate sobre o tema são fundamentais para compreensão e reflexão das possibilidades e consequências da escolha deste caminho para as UCs, ainda que estes devessem anteceder a tomada de decisão. As atividades turísticas e de lazer estão dentre os principais serviços a serem concedidos a iniciativa privada nos Parques Estaduais. Embora essas atividades estejam dentre os objetivos deste tipo de categoria de UC é preeminente ressaltar que a conservação deve nortear a gestão. O Estado é responsável por proteger importantes fragmentos de Mata Atlântica e Cerrado, em áreas com diferentes tipos de ocupação e pressão. Para tanto, necessita de investimento em pessoal capacitado, infraestrutura e equipamentos, além do apoio e diálogo com comunidades tradicionais, que tenham relação com as áreas. O que se observa atualmente é a precarização dos serviços prestados, em que os servidores públicos não têm plano de carreira e os guarda-parques, funcionários primordiais para essas áreas, estão se extinguindo e com eles todo um rico conhecimento. A maioria dos gestores é comissionada e em alguns casos não tem formação adequada para função. A fiscalização é terceirizada e patrimonial deixando que a Floresta propriamente dita, fique a mercê de usos indevidos e inadequados como ocupação irregular, extração de flora, caça, depósito de entulhos, entre outros. É fato que as atividades de uso público realizadas atualmente estão aquém das possibilidades dos parques. A concessão de serviços como alimentação, hospedagem, aluguel de equipamentos e implantação de estruturas para atividades de ecoturismo podem sim ser uma alternativa para dinamizar o uso desses espaços e gerar recursos. Há diversos exemplos de sucesso no exterior e no Brasil, que podem ser inspiradores. Porém, é necessário fundamentalmente que o Estado assuma a responsabilidade legal de salvaguardar as UCs, valorizando a carreira dos servidores públicos investindo em concursos e capacitações. Somente com uma estrutura organizacional fortalecida será possível conduzir com eficiência processos de concessão, que contribuam com a otimização de uso adequado desses espaços. As UCs fornecem serviços ambientais imensuráveis e dentre eles estão às oportunidades turismo, lazer e recreação.

PALAVRAS-CHAVE: Parques Estaduais; Uso Público; Gestão; Conservação. 


\section{ABSTRACT}

The discussion on the concession of protected areas is extremely important and has generated controversy in the State of São Paulo, due to the approval of the draft law № 16.260, that "authorizes the State Treasury to grant the exploitation of services or use of all or part of areas in state themselves." Research and debate on the subject are fundamental to understanding and reflection of the possibilities and consequences of choosing this way for protected area, even if they were to precede decision-making. Tourist and leisure activities are among the main services to be granted to private initiative in the State Parks. Although these activities are among the goals of that category of PA is paramount to emphasize that conservation should guide the management. The State is responsible for protecting important fragments of Atlantic Forest and Savannah, in areas with different types of occupation and pressure. Therefore, it needs investment in trained personnel, infrastructure and equipment, and support and dialogue with traditional communities that relate to the areas. What we currently see is the precariousness of services, where public servants have no career plan and park rangers, primary staff to these areas, they are dying off and with them a whole wealth of knowledge. Most managers are commissioned and in some cases do not have adequate training to function. The inspection is outsourced and property letting the forest itself, be at the mercy of undue and inappropriate uses such as illegal occupation, flora extraction, hunting, debris deposit, among others. It is true that the public use activities currently performed are beyond the means of the parks. The concession of services such as food, lodging, equipment rental and implementation of ecotourism activities to structures can indeed be an alternative to boost the use of these spaces and generate resources. There are many examples of success in Brazil and abroad, which can be inspiring. However, it is fundamentally necessary that the State assumes the legal responsibility to safeguard the protected areas, enhancing the careers of public servants investing in competitions and training. Only with a strengthened organizational structure will be possible to drive efficiently concession processes that contribute to the optimization of appropriate use of these spaces. PAs provide immeasurable environmental services and among them are the opportunities tourism, leisure and recreation.

KEYWORDS: State Parks; Public Use; Management; Conservation.

\section{Introdução}

Áreas naturais protegidas são criadas com o intuito de salvaguardar espaços, que detenham importantes atributos naturais e/ou culturais. Numa perspectiva antropocêntrica esses espaços fornecem serviços ambientais e devem ser conservados, a fim de garantir a manutenção destes benefícios para o ser humano como provisão de alimentos, produção de água, controle do clima, entre outros. Numa perspectiva biocêntrica a natureza possui valor por si só, independente de sua utilidade ou não para os seres humanos.

O processo de criação dessas áreas surge em contrapartida ao rápido processo de destruição da natureza que alcançamos, principalmente após a revolução industrial. Tem muita conexão com a emergência dos movimentos ambientalistas. Como nos mostra Urger (2000), o movimento ecológico é um dos mais abrangentes. A preservação do planeta - a preservação da vida interessa a toda à humanidade. Nesse sentido, o movimento ecológico é 
portador de valores e interesses que ultrapassam as fronteiras de classe, raça e nação.

Existem áreas protegidas em todo o mundo e são classificadas de diversas maneiras. A classificação internacional é feita pela IUCN (International Union for Conservation of Nature) em seis categorias (DUDLEY, 2008). Já o Brasil possui legislação própria denominada Sistema Nacional de Unidades de Conservação (SNUC) e reconhece 12 categorias de Unidades de Conservação (UC), que são divididas em dois grupos: as de uso sustentável e de proteção integral (BRASIL, 2004).

São áreas criadas e administradas pelo poder público. Quando federais a gestão cabe ao Instituto Chico Mendes de Conservação da Biodiversidade (ICMBio), órgão vinculado ao Ministério do Meio Ambiente, quando estaduais e municipais a gestão cabe as respectivas secretarias de meio ambiente. Invariavelmente há carência de recursos financeiros e humanos destinados à gestão efetiva dessas áreas. As políticas de gestão ambiental no Brasil entendem a manutenção dessas áreas como custo quando deveriam perceber como investimento em espaços que proporcionam benefícios fundamentais para manutenção da vida em todas as suas formas.

Tanto na classificação internacional quanto na nacional existe a categoria Parque Nacional, em destaque neste trabalho, tendo dentre os seus objetivos o uso para fins de turismo, recreação e lazer.

\section{Metodologia}

A pesquisa foi realizada de forma descritiva e exploratória utilizandose para coleta de dados a pesquisa bibliográfica e a legislação acerca dos temas Unidades de Conservação, gestão, planejamento, uso público e concessões, entre outros pertinentes ao problema do trabalho. Realizou-se também pesquisa em ambiente virtual de publicações e manifestações da mídia em relação ao tema abordado.

\section{Contextualização}

Os parques são áreas de domínio público instituído legalmente podendo ser nacional, estadual ou municipal. Há diversos tipos possíveis de governança desses espaços, a IUCN reconhece quatro grandes tipos que podem ser associados, são eles: governança pelo governo, governança compartilhada, governança privada e governança por populações indígenas e comunidades tradicionais (DUDLEY, 2008). O Brasil também reconhece esses tipos de governança, porém o debate e a implementação dessas variadas formas de gestão ainda é muito recente e divide a opinião de especialistas.

Os Parques Nacionais são administrados pelo ICMBio, os gestores, teoricamente, são analistas ambientais de carreira. Dentre os parques nacionais há dois exemplos emblemáticos que tiveram os serviços concedidos para a iniciativa privada, o Parque Nacional da Tijuca, RJ, que recebeu 2.945.355 de visitantes e o Parque Nacional do Iguaçu, PR, com 
1.642.093 de visitantes em 2015 (MMA, 2016). Esses dois exemplos são utilizados para defender a concessão das UCs, porém nem todas as Unidades de Conservação possuem atrativos tão singulares como as Cataratas, Patrimônio Natural da Humanidade.

Sabe-se que muitos parques nacionais, estão abandonados, sem infraestrutura mínima para atender o visitante e pessoas para garantir a proteção. Um exemplo notório é o Parque Nacional da Serra da Capivara, que possui patrimônio arqueológico com registros rupestres, intitulado patrimônio da humanidade, mas mesmo com toda sua relevância sofre com a falta de recursos e investimentos e está com risco iminente de ser fechado para visitação.

É fato que as atividades de uso público realizadas nos diferentes parques do Brasil atualmente estão aquém das possibilidades e potencial. Existe um conceito de "parques fortalezas" que restringe a visitação em nome da conservação das áreas. Porém, é preciso ter clareza que 0 investimento em infraestrutura e pessoas deve anteceder o aumento da visitação.

Este trabalho aborda as concessões das Unidades de Conservação tendo como objeto de estudo o Estado de São Paulo. Trata-se de um tema controverso entre especialistas. De forma geral, aqueles que são desfavoráveis defendem que as Unidades de Conservação são criadas para proteger biomas importantes, que prestam serviços ecossistêmicos fundamentais e que é responsabilidade do Estado investir e cuidar deste patrimônio, que não tem a função de gerar receita. Já aqueles que são a favor entendem que as áreas devem ser exploradas pelo turismo com a implantação de equipamentos e estrutura que atendam o visitante e que isso é cabível a iniciativa privada.

Essa discussão é extremamente importante e é preciso aprofundá-la. No Estado de São Paulo, tem gerado polêmica a recente aprovação da Lei № 16.260, de 29 de junho de 2016 que, "autoriza a Fazenda do Estado a conceder a exploração de serviços ou o uso, total ou parcial, de áreas em próprios estaduais". A pesquisa e o debate sobre o tema são fundamentais para compreensão e reflexão das possibilidades e consequências da escolha deste caminho para as UCs. Foram incluídas na lei, 25 áreas sendo 13 parques estaduais como o Parque Estadual da Cantareira e o Parque Turístico do Alto Ribeira (PETAR). Este último possui histórico de conflito de uso, pois o está inserido em áreas de remanescentes quilombolas.

As atividades turísticas e de lazer estão dentre os principais serviços a serem concedidos a iniciativa privada nos parques estaduais paulistas. Embora essas atividades estejam dentre os objetivos deste tipo de categoria de UC é preeminente ressaltar que a conservação deve nortear a gestão e ainda não se sabe, ao certo, como a mesma será feita. O Estado de São Paulo é responsável por proteger importantes fragmentos de Mata Atlântica e Cerrado, em áreas com diferentes tipos de ocupação e pressão. Para tanto, necessita de investimento em pessoal capacitado, infraestrutura e equipamentos, além do apoio e diálogo com comunidades tradicionais, que tenham relação com as áreas. 


\section{A gestão das Unidades de Conservação do Estado de São Paulo}

A gestão das UCs no Estado é responsabilidade da Fundação para a Conservação e a Produção Florestal do Estado de São Paulo, desde 2007 com implantação do Sistema Estadual de Florestas - SIEFLOR. Este foi concretizado através do Decreto Estadual n 51.453 , de 29/12/06 e alterado pelo Decreto Estadual no 54.079, de 04/03/2009. A criação do SIEFLOR acarretou diversas mudanças no que concerne a gestão das Unidades de Conservação do Estado, que anteriormente era realizada pelo Instituto Florestal (IF), instituição centenária de pesquisa em áreas florestais.

Em 2014 foi instituído o Sistema de Informação e Gestão de Áreas Protegidas e de Interesse Ambiental do Estado de São Paulo - SIGAP, como instrumento de planejamento, de integração e de publicidade das ações do Poder Público através do Decreto n 60.302 , de 27 de março de 2014. Em seu artigo Artigo 39 expõe que o SIEFLOR passa a integrar SIGAP como um subsistema (SÃO PAULO, 2014).

A Fundação Florestal foi criada em 1986, com objetivo de contribuir para a conservação, manejo e ampliação das florestas administradas pelo IF. A partir da instituição do SIEFLOR passa a ser a responsável pela gestão dessas Unidades de Conservação (SÃO PAULO, 2009). Ambas as instituições estão subordinadas a Secretaria de Meio Ambiente do Estado. Porém o IF é um órgão da administração direta e a FF da administração indireta, o que lhe confere, ao menos teoricamente, maior flexibilidade e autonomia, pois possui personalidade jurídica.

Dentre as principais diferenças observadas entre as instituições é a contratação de funcionários. Os servidores do IF são exclusivamente concursados e os da FF estão divididos em concursados e comissionados. O último concurso para Pesquisador Científico no IF foi em 2004 e na FF pra Analista de Recursos Ambientais em 2010.

Embora o estado esteja respaldado por diversas regulamentações, leis e decretos, que visam o planejamento e a gestão adequada das Unidades de Conservação, observam-se a precarização dos serviços prestados, em que os servidores públicos não têm plano de carreira e os guarda-parques, funcionários primordiais para essas áreas, estão se extinguindo e com eles todo um rico conhecimento. A maioria dos gestores das UCs é comissionada e em alguns casos não tem formação adequada para função. A fiscalização é terceirizada e patrimonial deixando que a Floresta, fique à mercê de usos indevidos e inadequados como ocupação irregular, extração de flora, caça, depósito de entulhos, entre outros.

A FF é responsável por 98 UCs, sendo que algumas como o Parque Estadual da Serra do Mar e o Parque Estadual da Cantareira possuem vários núcleos. Um dado alarmante exposto por Souza et al (2015), mostra a expressiva rotatividade de gestores nas UCs, em que foram verificadas 244 mudanças no período entre agosto de 2008 e fevereiro de 2015. O gestor das Unidades de Conservação possui papel crucial na implantação de programas, manejo e relação com entorno.

A legislação prevê que a gestão das UCs ocorra de forma participativa, porém embora existam alguns fóruns que permitam que isso 
ocorra, é um modelo ainda em construção. Os espaços existentes são os conselhos consultivos e deliberativos, mas que na maioria das vezes são instituídos apenas formalmente. A tomada de decisão ainda está centrada ao órgão gestor, que em algumas situações negligenciam os interesses e direitos de comunidades do entorno.

\section{As concessões}

As propostas de descentralização, desestatização, terceirização, características da reforma administrativa gerencial dos anos de 1990, influenciaram diversas políticas públicas, inclusive na área ambiental (RODROGUES; GODOY, 2013).

A compreensão do tema em questão requer o entendimento das diversas formas de gestão possíveis à administração pública, que podem ser estatais e não estatais. Nos modelos estatais têm-se órgãos da administração direta e órgãos da administração indireta. Como visto anteriormente as Unidades de Conservação do Estado de São Paulo, até o ano de 2006 eram administradas pelo Instituto Florestal, órgão da administração indireta. Com a instituição do SIEFLOR passa a ser gerida pela Fundação Florestal, órgão da administração indireta. O ICMBio, responsável pela gestão das UC federais, também é um exemplo de administração indireta se tratando de uma autarquia.

Tais instituições se caracterizam por maior autonomia, especialização e capacidade administrativa com orçamento próprio em alguns casos, porém devem zelar pelos princípios da gestão pública como legalidade e impessoalidade, por exemplo. Ainda são exemplos desse tipo de administração as empresas públicas e sociedades de economia mista (SEMEIA, 2015).

Compreender as características das modalidades de prestação de serviços é fundamental pra planejamento das atividades de uso público. No caso dos parques é preciso considerar aspectos econômicos, perfil de visitantes, vocação da área, impactos, entre outros (RODROGUES; GODOY, 2013).

Dentre os modelos de gestão não estatais estão àqueles realizados por instituições, que estão fora da estrutura organizacional do poder público. $\mathrm{O}$ instrumento regulador é o contrato, que pode ser firmado para diversas finalidades. Contratos claros e específicos são vistos como porta de entrada para o bom relacionamento entre o poder público e a iniciativa privada (SEMEIA, 2013).

Destaca-se neste contexto o terceiro setor, que teve expressivo aumento nas últimas décadas, notadamente na área ambiental, com as Organizações não Governamentais (ONGs), as Organizações Sociais (OS) e as Organizações da Sociedade Civil de Interesse Público (OSCIP). Estas organizações estão aptas a receber recursos públicos, pois possuem os requisitos necessários para executarem determinada função ou atividade (SEMEIA, 2015). 
Pode-se citar como exemplo na Fundação Florestal a elaboração de planos de manejo como o do PE de Campos de Jordão elaborado pelo Instituto Ekos Brasil e a realização de cursos de capacitação realizados pelo WWF - Brasil. A primeira trata-se de uma OSCIP e a segunda uma ONG, ambas com reconhecida atuação na área ambiental. $A$ eficiência $e$ flexibilidade são as principais vantagens para escolha desse tipo de atuação, embora normas próprias da administração pública também recaiam sobre elas.

O uso por terceiros de bens públicos pode ser realizado por concessões, por autorização ou permissão de uso. A autorização e permissão são atos precários e vem sendo utilizados em algumas UCs paulistas. Nestes tipos de modelo a instituição gestora (Fundação Florestal), autoriza a realização de serviços específicos de alimentação e venda de souvenirs, por exemplo. No Parque Estadual de Campos de Jordão, pode-se encontrar lanchonete, café e aluguel de bicicleta, no PETAR os monitores são de uma Associação e no Parque Estadual de Intervales há um restaurante administrado por particular. São casos de permissão de uso de um bem público, mas que são de interesse do coletivo, nesses casos os visitantes das Unidades de Conservação.

A realização de qualquer modalidade de exploração ou prestação de prestação de serviços deve ser orientado pelas legislações específicas que são: a Lei de Concessões, Lei de Licitações e Lei das Parcerias PúblicoPrivadas (PPP) (RODRIGUES e GODOY, 2013). A Lei № 16.260, de 29 de junho de 2016, tem sido alvo de críticas por diversos setores envolvidos com as UCs. A referida lei trata da modalidade concessão que tem como característica:

Nas concessões de serviços públicos, o concessionário recebe o direito de explorar uma atividade que é de titularidade do Poder Público, mas se obriga a ofertar aos cidadãos utilidades e serviços de qualidade. Trata-se de um modelo no qual o governo não aliena seus bens a terceiros e, neste sentido, ele é completamente diferente de uma privatização, sendo equivocada a ideia que muitas vezes circula nos debates, de que parcerias em UC seriam uma forma de privatização (SEMEIA, 2015).

De acordo com a citada lei:

Artigo 1ํ - Fica a Fazenda do Estado autorizada a conceder a exploração dos serviços ou o uso de áreas, ou parte de áreas, inerentes ao ecoturismo e à exploração comercial madeireira ou de subprodutos florestais, pelo prazo de até 30 (trinta) anos, dos próprios estaduais constantes do Anexo desta lei (SÃO PAULO, 2016). 
Estão inclusas 25 Unidades de Conservação entre Parques, Estações Experimentais e Florestas. Dentre estas áreas 13 são parques estaduais, a saber: PE Campos do Jordão, PE Cantareira, PE Intervales, PE Turístico do Alto Ribeira, PE Caverna do Diabo, PE Serra do Mar (Núcleo Santa Virgínia), PE Serra do Mar (Núcleo São Paulo), PE Jaraguá, PE Carlos Botelho, PE Morro do Diabo, PE Ilha do Cardoso, PE De Ilha Bela, PE Alberto Löfgren, PE Caminhos do Mar. Vale ressaltar que não existe Núcleo São Paulo no PE Serra do Mar, o que demostra que os técnicos da instituição gestora não participaram da elaboração da lei (SÃO PAULO, 2016).

Estes parques estão localizados em regiões distintas com ambientes complexos e singulares. O Vale do Ribeira, por exemplo, onde se localizam quatro das UCs, é uma região extremamente importante, que abriga parcela significativa de Mata atlântica, possui comunidades tradicionais e um rico sistema cárstico. Já a Região Metropolitana de São Paulo, onde estão três dos parques selecionados, tem toda a complexidade e pressão do meio urbano na maior metrópole do país.

O Artigo $2^{-}$trata dos objetivos da lei, dos quais dois tratam especificamente de ecoturismo, recreação e lazer, são eles:

I - permitir, criar e favorecer condições à exploração do potencial ecoturístico das áreas;

XIV - criar e favorecer condições e promover a educação ambiental, a recreação e o lazer em contato com a natureza (SÃO PAULO, 2016).

Nota-se que os objetivos são genéricos e não especificam quais atividades podem ser realizadas. Vale ressaltar que a lei ainda deverá ser regulamentada. A principal crítica à referida lei é que os interessados e afetados não foram consultados e que não há clareza em que condições se darão as concessões, já que cada uma das áreas possui características próprias. Ações como essa revelam a fragilidade do aspecto participativo na gestão das Unidades de Conservação. Técnicos da instituição gestora também se manifestaram contrários à promulgação da lei como pode ser consultado no blog do Conselho de Representantes dos Funcionários da Fundação Florestal em que se posicionam. De acordo com o mesmo:

Se é verdade que hoje a capacidade de atendimento ao visitante nas áreas protegidas do Estado é deficiente, é preciso esclarecer que trata-se de condição criada pelos sucessivos atos de sucateamento das instituições que fazem gestão das UCs pelas consecutivas ações do governo estadual. Não tem sido por falta de alerta, já que constantemente este Conselho tem enviado cartas à Diretoria Executiva da FF, e publicado estudos/ documentos sobre o reduzido quadro de funcionários e a precariedade das condições de trabalho, que tornam nossas UCs cada dia mais vulneráveis às ações de degradação ambiental (CFR, 2016). 
Para qualificar o debate sobre a questão é preciso ter claro os conceitos das diversas possibilidades e instrumentos da gestão dos bens públicos. O termo "privatização" tem sido utilizado de maneira equivocada em diversas mídias para criticar a referida lei como nos exemplos que segue:

"Assembleia aprova projeto de Alckmin para 'privatizar' 25 parques no Estado" (Folha de São Paulo, 07-06-2016).

“Assembleia aprova projeto que 'privatiza' 25 parques de SP (Estado de São Paulo, 07-06-2016).

"Privatização de parques paulistas é aprovada sem consulta às comunidades afetadas" (Instituto Socioambiental (ISA), 07-06-2016)

Embora a lei seja genérica e não deixa claro como se darão as concessões é preciso compreender do que se trata. É necessário destacar que artigos importantes foram retirados do texto inicial que se refere ao retorno dos recursos para as Unidades.
Artigo 60 - Vetado:
I - vetado;
II - vetado
Cuja redação era:
Artigo 6ำ - Os recursos obtidos com as concessões serão destinados exclusivamente para a gestão das Unidades de Conservação e demais áreas de que trata esta lei, na forma estabelecida em regulamento, garantindo no mínimo:
I - até 50\% (cinquenta por cento), e não menos que $25 \%$ (vinte e cinco por cento), na implementação, manutenção e gestão da própria unidade;
II - até $50 \%$ (cinquenta por cento), e não menos que 15\% (quinze por cento), na implementação, manutenção e gestão de outras unidades.

A prestação de serviços de uso público demanda investimentos que promovam a qualidade, segurança e o menor impacto ambiental durante a realização das atividades. Em contrapartida, podem elevar o valor a ser cobrado para o uso dos parques. Porém, não se trata apenas dos interesses do empreendedor. O Estado e os usuários são agentes fundamentais que devem ser equacionados, pois atores têm interesses diferentes e legítimos na conservação e uso das áreas (RODRIGUES; GODOY, 2013).

A concessão de serviços como alimentação, hospedagem, aluguel de equipamentos e implantação de estruturas para atividades de ecoturismo podem sim ser uma alternativa para dinamizar o uso desses espaços e gerar recursos. Há diversos exemplos de sucesso no exterior e no Brasil, que podem ser inspiradores. Porém, é necessário fundamentalmente que o Estado assuma a responsabilidade legal de salvaguardar as UCs, valorizando a carreira dos servidores públicos investindo em concursos e capacitações. 
Somente com uma estrutura organizacional fortalecida será possível conduzir com eficiência processos de concessão, que contribuam com a otimização e o uso adequado desses espaços. É preciso ter claro que o Estado não poderá transferir suas responsabilidades para terceiros, pois terá sempre que fiscalizar e monitorar os serviços prestados considerando aspectos sociais, econômicos e ambientais.

\section{Conclusão}

Os parques são áreas protegidas instituídas com objetivo de conservação do patrimônio natural e cultural, mas também são destinadas ao uso público, onde o visitante pode entrar em contato com o meio natural e compreender a relação e importância desses espaços. O uso público de um parque é o programa que mais requer investimento, pois carece de infraestrutura adequada e pessoas capacitadas. Quanto maior a visitação, mais investimento será necessário.

Dentre as possibilidades de uso dos parques está à prática do turismo, mais especificamente do ecoturismo. O Brasil se destaca pelo significativo potencial desse segmento que possui exponencial crescimento. Este fato também é reflexo da desconexão do homem com o meio natural, que busca este contato no tempo livre. Há atualmente uma indústria em torno do setor com produção de equipamentos, acessórios, vestimentas e a venda de um imaginário com lugares paradisíacos e intocados.

Os parques, de forma geral, são espaços ideais para a prática dessa atividade. Como já mencionado há no país diversidade de paisagens e biomas como Cerrado, Mata Atlântica e a emblemática Amazônia. Sabe-se, porém que o desenvolvimento de atividades de uso público tem ocorrido de maneira muito tímida diante do potencial, salvo algumas exceções como Parque Nacional do Iguaçu e Parque Nacional da Tijuca. Porém, como ressaltando anteriormente as características dos parques são diversas e alguns não possuem atrativos tão singulares com demanda potencial de visitação, mas possuem relevância para conservação carecendo de investimento para garantir sua proteção.

É preciso estimular o debate e a pesquisa para que seja possível garantir que essas áreas sejam espaços democráticos de uso público e conservação dos biomas. Este estudo demonstrou que as concessões para a realização de atividades de ecoturismo pode ser uma alternativa para incremento de uso ecoturísticos dos parques estaduais. Porém, a instituição da Lei antecedeu o debate e a consulta aos diversos interessados. De acordo com a mesma, deverá ocorrer a regulamentação no prazo de 180 dias a partir de sua sanção. É fundamental que esta regulamentação seja acompanhada e realizada de forma participativa com equipe técnica e os diversos atores envolvidos nessas áreas para que sejam garantidos os direitos daqueles que são diretamente afetados pela gestão desses espaços. Exemplos de sucesso devem sim ser utilizados como referência, porém é necessário equalizar as especificidades das Unidades de Conservação em questão e ampliar o debate para que não haja prejuízos ambientais e sociais no futuro. 


\section{Referências Bibliográficas}

BRASIL. Ministério do Meio Ambiente. Sistema Nacional de Unidades de Conservação da Natureza. Brasília, DF, 2004.32p.

CONSELHO DE REPRESENTATES DA FUNDAÇÃO FLORESTAL (CRF) (Blog). Nota pública sobre o PL 249/2013 - concessão de parques estaduais. Disponível em: <http://blogdocrf.blogspot.com.br/2016/06/notapublica-sobre-o-pl-2492013.html> Acesso em: 20 jun 2016.

DUDLEY, N. (Editor). Guidelines for Applying Protected Area Management Categories. Gland, Switzerland: 2008.

RODRIGUES, C.G.O.; GODOY, L.R.C. Atuação pública e privada na gestão de Unidades de Conservação: aspectos socioeconômico prestação de serviços de apoio à visitação em parques nacionais. Revista Desenvolvimento e Meio Ambiente, v. 28, pp. 75-88. Editora UFPR: 2013.

SÃO PAULO (Estado). Lei no 16.260, de 29 de junho de 2016. Autoriza a Fazenda do Estado a conceder a exploração de serviços ou o uso, total ou parcial, de áreas em próprios estaduais que especifica e dá outras providências correlatas. Diário Oficial: 2016.

SÃO PAULO (Estado). Decreto no 51.453, de 29 de dezembro de 2006 Cria o Sistema Estadual de Florestas - SIEFLOR e dá providências correlatas. São Paulo: 2016.

SÃO PAULO (Estado). Decreto no 54.079, de 4 de março de 2009 Altera os artigos 5, 6ำ 9 9, acrescenta o artigo 9A e modifica os Anexos do Decreto no 51.453, de 29 de dezembro de 2006, que cria o Sistema Estadual de Florestas - SIEFLOR e dá providências correlatas. São Paulo: 2009.

SÃO PAULO (Estado). Decreto no 60.302, de 27 de março de 2014. Institui - Sistema de Informação e Gestão de Áreas Protegidas e de Interesse Ambiental do Estado de São Paulo - SIGAP e dá providências correlatas. São Paulo, 2014.

SEMEIA. Modelos de concessão em parques norte-americanos. Biblioteca Semeia - Novembro, 2014.

SEMEIA. Modelos de gestão aplicáveis às Unidades de Conservação do Brasil. Instituto Semeia. - São Paulo: Semeia, 2015. 59 p.

SOUZA, F.A.Z. et al. Mudar ou não mudar, eis a gestão? A situação dos gestores de Unidades de Conservação no Estado de São Paulo. Anais do VIII CBUC - Trabalhos Técnicos 2015. Curitiba: 2015. Disponível em: http://eventos.fundacaogrupoboticario.org.br/CBUC/TrabalhosTecnicos?ids= 1495 > Acesso em: 10 de jul 2016.

UNGER, N.M. O encantamento do humano: ecologia e espiritualidade. São Paulo: Edições Loyola, 2000. 
Alessandra Freire Reis: Escola Superior de Agronomia Luiz de Queiroz, Piracicaba, SP, Brasil.

E-mail: freire.le@gmail.com

Link para o currículo Lattes: http://lattes.cnpq.br/7759087059213016

Odaléia Telles Marcondes Machado Queiroz: Escola Superior de Agronomia Luiz de Queiroz, Piracicaba, SP, Brasil.

E-mail: odaleiaq@terra.com.br

Link para o currículo Lattes: http://lattes.cnpq.br/6995118783898309

Data de submissão: 30 de agosto de 2016

Data de recebimento de correções: 05 de maio de 2017

Data do aceite: 05 de maio de 2017

Avaliado anonimamente 